\section{Trends in the use of Part II of the Mental Health Act 1983 in seven English local authority areas}

\author{
PAUL LELLIOTT and BERNARD AUDINI
}

Part II of the Mental Health Act 1983 allows for the formal admission to hospital of people in England and Wales. Sections 4 and 2 of the Act allow detention for assessment for periods of up to $72 \mathrm{~h}$ and 28 days respectively; Section 3 allows admission for treatment for up to 6 months. According to data collected routinely by the Department of Health, there has been a substantial increase in the number of admissions under Part II during the past decade or so (Department of Health, 1999). However, the way in which the data are collected means that these central returns cannot be used to identify whether this increase has been uniform over all age groups, across different ethnic groups and in both genders. Data-sets collected for local purposes by local authorities and National Health Service trusts do permit such analyses.

\section{METHOD}

\section{Identification and management of data-sets}

The data-sets of seven English local authorities that had collected information continuously between 1991 and 1997 were included in the analyses of trends. The local authority information had been collected by the approved social workers who coordinated the Mental Health Act assessments. The way in which the data-sets were identified and how they were made compatible, including the way in which data about ethnicity were recoded, has been described elsewhere (Audini \& Lelliott, 2002). Diagnosis had been coded using a variety of classification systems. This variable was recoded into five very broad categories - psychotic disorder, neurotic and mood disorders, personality disorder, dementia and learning disability.

Census data were used to standardise the rates of formal admission under the Mental Health Act for specific subgroups of the population defined by age, gender and ethnicity. Data were analysed using SPSS version 8 (SPSS, 1997) and STATA version 5 (StataCorp, 1997). For most analyses, incidents of admission under Sections 2, 3 and 4 were combined to give rates of use of admission sections under Part II of the Act.

\section{RESULTS}

\section{Characteristics of the local authorities}

The combined catchment population of the seven local authority areas was 2.9 million persons. The mean Jarman Underprivileged Area Score (Jarman, 1983) of the seven areas was 111, and their mean score on the Mental Illness Needs Index (Glover et al, 1998) was 102.2. This suggests that the seven sites were skewed towards the more socially deprived end of the range for all local authorities in England.

\section{Characteristics of those detained}

The combined data-set contained 10926 incidents of detention over 7 years. It is not known how many people this comprises because the data-sets obtained from local authorities do not include unique personal identifiers. It is inevitable that some people would have been detained on more than one occasion. Fifty-three per cent of detentions were of women; $87 \%$ were of White people, $7 \%$ of Black, $4.5 \%$ of Asian and $1.5 \%$ of people from other ethnic minority groups. The 'other' category for ethnic minority group contained only 158 cases and was considered too small for analyses of trends over the 7-year period. The mean age of those detained was 44.9 years $(95 \%$ CI 44.6-45.3) and the median age was 40 years. Only three of the broad diagnostic categories contained more than $2 \%$ of the cases (psychosis $71 \%$; neurotic and mood disorders 13\%; dementia 6.6\%). Detentions under Section 2 accounted for $55 \%$ of the cases $(n=6024)$, Section 4 for $4 \%$ $(n=431)$ and Section 3 for $41 \%(n=4471)$.

\section{Overall change in rate of use of Part II}

Between 1991 and 1997 the annual rate of use of Part II in the seven local authority areas increased by $32 \%$, from 57 to 75 per 100000 total population. All of this increase was accounted for by a steep rise in the rate of use of the Act after 1993 (Fig. 1). The rate of detentions under the 


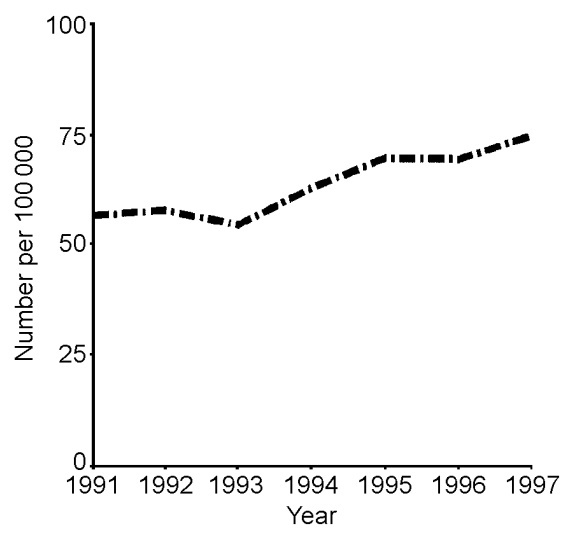

Fig. I Change in number of detentions under Part II sections per 100000 population for each year between 1991 and 1997.

treatment section of the Act (Section 3) increased by $44 \%$ during this period. This was about twice the rate of increase of detentions for assessment $(24 \%$ for Section 2 and $21 \%$ for Section 4 ).

\section{Differences between subgroups}

\section{Gender}

When standardised for gender-specific populations, the rate of increase in the use of Part II of the Act was greater for men than for women. For men it increased by $38 \%$, from 55 to 76 per 100000 , and for women by $26 \%$, from 58 to 73 per 100000 . The difference between genders was most marked for the younger age group. The increase for men aged $20-45$ years was $43 \%$, from 88 to 126 per 100000 , and for women of this age it was $28 \%$, from 72 to 92 per 100000 .

\section{Ethnicity}

The rate of use of the Act increased for all three of the main ethnic subgroups. There was a $31 \%$ increase for White people (from 51 to 67 per 100000 of the White population), a $38 \%$ increase for Black people (from 288 to 397 per 100000 of the Black population) and a $48 \%$ increase for Asian people (from 80 to 118 per 100000 of the Asian population).

\section{Diagnostic categories}

The rate of increase of admissions of people from different diagnostic categories mirrored that of the overall increase in use of Part II, with the notable exception of admissions for dementia. Although these were few in absolute terms, the rate of admissions of people with dementia trebled, from 2.0 to 5.6 per 100000 total population.

\section{DISCUSSION}

The data suggest that there has been a marked increase in the use of Part II of the Mental Health Act in this sample of seven local authority areas. It is possible that this is an artefact of, for example, improvements in the completeness of data collection. However, we were unable to identify features of the data collection process for example, changes in the data schedules - that could have introduced such a systematic bias. Also, the $32 \%$ increase in the use of Part II of the Act over the 7-year period is consistent with the $57 \%$ increase between 1988 and 1998 reported by the Department of Health (Department of Health, 1999) and the $63 \%$ increase reported for the period between 1984 and 1996 (Hotopf et al, 2000).

When interpreting the findings, it is important to remember that the data-sets did not allow for the identification of individuals who might have been detained more than once during the period under review. It is possible that some groups of the population might be more likely to be admitted repeatedly under the Mental Health Act. If this is the case, then they would be overrepresented in the sample.

\section{Why are formal admission rates increasing?}

Assuming that it reflects a real trend, the increase in formal admissions during the 1990s has occurred despite a continuous process of reduction in the numbers of psychiatric beds (Lelliott, 1996; Sainsbury Centre for Mental Health, 1998). This apparent paradox is perhaps a result of the shortage of psychiatric beds (Audini et al, 1999). This creates two types of pressure: first, pressure not to admit patients, perhaps leading to deterioration to the point where admission is required under the Mental Health Act; and second, pressure to discharge patients early, perhaps resulting in a greater likelihood of readmission, and perhaps of readmission under a section of the Mental Health Act. Furthermore, the conditions on acute psychiatric wards have deteriorated (Sainsbury Centre for Mental Health, 1998) perhaps to the point where coercion is more likely to be required to 'persuade' patients to reside there. It is likely that this deterioration is in part due to the increased threshold for admission. This creates a concentrating effect, resulting in a case-mix of patients with more severe disability and disturbance on acute psychiatric wards (Lelliott $e t$ al, 1995).

A further paradox is that as bed numbers have reduced, so mental health practitioners have become more safety conscious. The level of awareness of risk management has increased over the past decade. This has been driven by a spate of inquiries into homicides committed by people with a mental illness (Sheppard, 1996) and the preoccupation of successive governments with protection of members of the public from attacks by people with a mental illness. This preoccupation is demonstrated by the issuing of guidance such as the Care Programme Approach and by proposed new mental health legislation, designed to increase the intensity of care and surveillance of people in the community who are deemed to pose a risk. Thus, although the overall threshold for admission might have increased, it might also have been skewed towards those who are perceived as being more at risk of acting violently and of being non-compliant. It is likely that admissions of such people are more likely to require the use of the Mental Health Act.

The data provide some circumstantial support for this hypothesis. First, the rate of increase in Part II admissions in these seven local authority areas accelerated from 1994 onwards. This was the year when the most highly publicised inquiry into a homicide by a person with a mental illness published its report. The report into the case of Christopher Clunis (Ritchie et al, 1994), perhaps more than any other factor, led to a greater awareness of risk management by mental health services. Second, there has been a greater increase in the admission under section of men than women and, in particular, of young men. Most of the subjects of homicide inquiries have been men in the age range 20-45 years and it is this group of people with a mental illness who are perhaps most at risk of acting violently, or are perceived to be. It should be noted, however, that data collected routinely by the Department of Health does not show a greater increase in the rate of formal admissions after 1993 (Hotopf et al, 2000).

\section{Why do so many more formal admissions involve young men?}

The total number of people occupying a psychiatric bed fell steadily between 1982 and 1992. This was consistent with a great reduction in bed numbers. However, after 
slowly falling between 1982 and 1986, the number of people aged 15-44 years who were in a psychiatric hospital actually increased steadily over the subsequent 6 years. Most of the increase in numbers of young people in hospital was accounted for by young men (Lelliott, 1996).

Changes in society have had a different impact on men from that on women in some important respects that might have a bearing on how mental illness presents. For example, the Office for National Statistics of England and Wales (Office for National Statistics, 2002) has reported that the recession of the 1980s 'had a much greater effect on unemployment among men than among women' and also that 'the largest increase in one-person households [over the past 30 years] has been among men under the age of $65^{\prime}$. The great increase in suicide rates among young men over the past 30 years, which has not occurred in the female population, might be another indicator of these changes (Office for National Statistics, 2002).

\section{Are most people with dementia being admitted?}

The nearly three-fold increase in the rate of admission under Part II of people diagnosed as having dementia is interesting but should be interpreted cautiously. The absolute number of cases was small and the assignment of diagnosis was made by approved social workers and not by psychiatrists. If the finding is replicated, it might herald the early stages of an effect on the prevalence of dementia as the proportion of older people in the population increases.

\section{The value for service-planning of data about trends}

The trends identified in these seven local authority areas, if they reflect changes across the country, support the need for services tailored for and targeted at the population of young men with mental illness, who seem increasingly at risk of compulsory admission and treatment. This small-scale, opportunistic study illustrates the value of trends data for this type of long-term planning and service development, both locally and nationally. The enactment of the proposed new mental health legislation in different parts of the UK will perhaps be an opportunity to develop national systems for the collection of better-quality and more-detailed information about the use of the Mental Health Act.

\section{CLINICAL IMPLICATIONS}

- The rate of use of Part II of the Mental Health Act 1983 has increased despite a reduction in psychiatric bed numbers.

- There is a need for services that are tailored for and targeted at the population of young men with mental illness, who seem increasingly at risk of compulsory admission and treatment.

- The enactment of new mental health legislation in different parts of the UK should be accompanied by the introduction of better national systems for the collection of information about formal admissions.

\section{LIMITATIONS}

The sample in this study is of incidents of detention under the Act; it is not known how many people this comprises.

- It is not known whether the trends identified in these seven local authorities reflect the pattern across the rest of the country.

- The finding of a large increase in the rates of detention for people with a diagnosis of dementia is based on a small sample and needs to be replicated.

PAUL LELLIOTT, MRCPsych, BERNARD AUDINI, BSc, Royal College of Psychiatrists' Research Unit, London, UK

Correspondence: Dr Paul Lelliott, Royal College of Psychiatrists' Research Unit, 6th Floor, 83 Victoria Street, London SWIH OHW, UK. Tel: 02072270820

(First received 25 March 2002, final revision 21 August 2002, accepted 30 August 2002)

\section{ACKNOWLEDGEMENTS}

The authors thank those who provided the datasets. In particular we are grateful to Barbara Hatfield, Director of Social Work Studies at the University of Manchester, who provided the northwest local authority data-set for use in this study The study would not have been possible without her assistance in the early stages. The findings and conclusions do not necessarily represent the views of the Royal College of Psychiatrists.

\section{REFERENCES}

Audini, B. \& Lelliott, P. (2002) Age, gender and ethnicity of those detained under Part II of the Mental Health Act 1983. British Journal of Psychiatry, 180, 222-226.

—, Duffett, R. \& Lelliott, P. (1999) Over-occupancy in London's acute psychiatric units - fact or fiction? Psychiatric Bulletin, 23, 590-594.

Department of Health (1999) In-patients Formally Detained in Hospitals under the Mental Health Act 1983 and other Legislation, England: 1988-89 to 1998-99. London: Government Statistical Service.

Glover, G. R., Robin, E., Emami, J., et al (1998) A needs index for mental health care. Social Psychiatry and Psychiatric Epidemiology, 33, 89-96.
Hotopf, M., Wall, S., Buchanan, A., et al (2000) Changing patterns in the use of the Mental Health Act 1983 in England, 1984-1996. British Journal of Psychiatry, I76, 479-484.

Jarman, B. (1983) Identification of underprivileged areas. BMJ, 286, 1705-1709.

Lelliott, P. (1996) Meeting the accommodation needs of the most severely mentally ill. Journal of Interprofessional Care, 10, 24I-247.

_, Audini, B. \& Darroch, N. (1995) Resolving

London's bed crisis: there might be a way, is there a will? Psychiatric Bulletin, 19, 273-275.

Office for National Statistics (2002) National Statistics Statbase. www.statistics.gov.uk/statbase/ xdataset.asp.

Ritchie, J. H., Dick, D. \& Lingham, R. (1994) The Report of the Inquiry into the Care and Treatment of Christopher Clunis. London: HMSO.

Sainsbury Centre for Mental Health (1998) Acute Problems: A Survey of the Quality of Care in Acute Psychiatric Wards. London: Sainsbury Centre for Mental Health.

Sheppard, D. (1996) Learning the Lesson. Mental Health Inquiry Reports Published in England and Wales between 1969-1994 and their Recommendations for Improving Practice (2nd edn). London: Zito Trust.

SPSS (1997) SPSS for Windows Base Systems User's Guide, Release 8. Chicago, IL: SPSS Inc.

StataCorp (1997) STATA Statistical Software: Release 5.9. College Station, TX: Stata Corporation. 